\title{
Chemical Characterization of PM10 Particulate Matter in the Ambient Air of a Region of Central Italy (Umbria)
}

\author{
Mara Galletti ${ }^{1}$, Silvia Castellini' ${ }^{2}$, Andrea Pileri' ${ }^{1}$, Caterina Austeri' ${ }^{1}$, Marco Pompei ${ }^{1}$, \\ Monica Angelucci' \\ ${ }^{1}$ ARPA Umbria, Perugia, Italy \\ ${ }^{2}$ Department of Chemistry, Biology and Biotechnology, University of Perugia, Perugia, Italy \\ Email: m.galletti@arpa.umbria.it
}

Received 3 July 2015; accepted 28 August 2015; published 1 September 2015

Copyright (C 2015 by authors and Scientific Research Publishing Inc.

This work is licensed under the Creative Commons Attribution International License (CC BY). http://creativecommons.org/licenses/by/4.0/

(c) (i) Open Access

\section{Abstract}

Atmospheric particulate matter is a critical factor for many regional urban areas of Umbria (Central Italy region). During 2013 the monitoring air quality network, managed by ARPA Umbria, has been upgraded to Legislative Decree of 13 August 2010, n.155 and an analytical study about chemical composition of PM10 (Particulate Matter with diameter of 10 micrometres or less) over all the region has been started. The PM10 filters have been analyzed for $\mathrm{Benzo}(\alpha) \mathrm{Pyrene}, \mathrm{Pb}, \mathrm{Cr}, \mathrm{Ni}$ and Cd to check compliance with limits or target values defined in Italian regulation (Legislative Decree of 13 August 2010, n.155); other parameters, like US-EPA list Polycyclic Aromatic Hydrocarbons (PAHs), Polychlorinated Dibenzo-p-Dioxins and Polychlorinated Dibenzo Furans (PCDD/ Fs), Polychlorinated Biphenyls (PCBs), Organic Carbon/Elemental Carbon (OC/EC) and Levoglucosan were analyzed because they are toxic or because they identify particular pollutant sources. The data obtained showed a large and diffusive biomass burning contribution, widely used in the Umbria Region both for domestic heating in traditional fireplaces and for combustion of pruning residues. In particular the urban sites of Terni and sub-urban site near Terni (Narni), both lying in the Terni basin called "Conca Ternana", showed a chemical composition of PM10 that suggests a very large anthropization. This area is the principal industrial reality in the Central Italy because there is a steel production plant, a Municipal solid waste (MSW) burning plant and a chemical plant.

\section{Keywords}

Particulate Matter, Chemical Composition, Biomass Burning

\footnotetext{
${ }^{*}$ Corresponding author.

How to cite this paper: Galletti, M., Castellini, S., Pileri, A., Austeri, C., Pompei, M. and Angelucci, M. (2015) Chemical Characterization of PM10 Particulate Matter in the Ambient Air of a Region of Central Italy (Umbria). International Journal of Analytical Mass Spectrometry and Chromatography, 3, 47-53. http://dx.doi.org/10.4236/ijamsc.2015.33006
} 


\section{Introduction}

Particulate matter in atmosphere is a significant problem because of its environmental and human health impacts [1].

Primary sources of particulate matter are vehicular traffic, biomass burning, industrial combustion processes, and heating plant. When Particulate Matter (PM) is emitted, it can spread very far; during the path it interacts with the substances in the atmosphere evolving into secondary pollutants [2].

The event is very complex and a complete particulate matter characterization is indispensable to identify the sources. When sources are known it is possible to achieve the objectives fixed by the European laws, and moreover if chemical composition of the sources is known, it is possible to study their effects on the human health.

During 2013 the air quality network managed by Regional Environmental Protection Agency (Agenzia Regionale per la Protezione Ambientale, ARPA) Umbria has been upgraded to Italian regulation (Legislative Decree of 13 August 2010, n.155), the adjustment concerned instrumentation and monitoring sites; moreover some extra urban areas, being monitored only during short periods of time in the past, have been inserted in the network.

The evaluation of the dataset showed bad results for PM10 and Benzo $(\alpha)$ Pyrene not only for the "Conca Ternana" monitoring sites, where there are many industries and weather and topography conditions are unfavorable to the spread of pollutants, but also in the other small towns and suburban areas [3].

This fact was observed in many Italian cities, and focused studies showed one common source: biomass burning [4] [5].

Biomass burning, especially by little plants without any emission control system like fireplaces, can contribute to the particulate emissions also in rural areas. This particulate can transport also toxic compounds like PAHs and PCDD/Fs [6].

These facts have induced ARPA Umbria to make an intensive study of PM10 chemical composition. In this article the results of the chemical analysis of PAHs, PCDD/Fs, PCBs, Levoglucosan and recently also EC/OC are shown.

Especially levoglucosan (biomass burning specific marker) can help about the weight of biomass burning in atmospheric PM [7].

\section{Experimental}

\subsection{Sampling}

Particulate matter (PM10) was collected during a year of monitoring from September 2013 to September 2014 at eleven different locations scattered throughout the Umbria region, representing urban and sub-urban areas (Figure 1). The aerosol was collected on $47 \mathrm{~mm}$ quartz fiber filters QM-A (Whatman Corp., OR, USA) by PM10 SWAM Dual Channel (FAI instruments srl, Rome, Italy) or OPSIS SM200 (Opsis AB, Furulund, Sweden), the collection time was 24 hours. On different portions of filter, appropriately grouped, are determinated: Levoglucosan, PAHs, PCDD/Fs, PCBs and Metals.
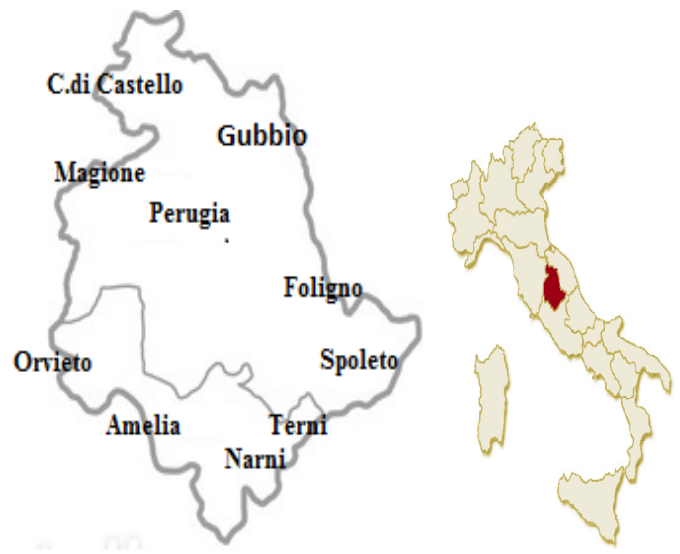

\begin{tabular}{cc}
\hline Location & Type of station \\
\hline Terni B.Rivo & Urban/Background \\
Terni Le Grazie & Urban/Traffic/Industrial \\
Narni & Sub-urban/Background \\
Amelia & Urban/Background \\
Orvieto & Sub-urban/Background \\
Spoleto & Urban/Traffic \\
Foligno & Urban/Background \\
Perugia & Urban/Traffic \\
Magione & Sub-urban/Background \\
Città di Castello & Urban/Background \\
Gubbio & Urban/Background \\
\hline
\end{tabular}

Figure 1. Map of studied area with location of sampling sites. 


\subsection{Chemical Analysis}

\subsubsection{Levoglucosan}

Part of the filter samples were extracted with a mixture of dichloromethane-methanol (80:20, v/v) (pesticide grade, Fluka Sigma-Aldrich, MO, USA) by Dionex 350 ASE Accelerated Solvent Extractor (Thermo Fisher Scientific Inc., Waltham, Massachusetts, USA), following a protocol reported in Table 1. After derivatization with a mixture containing reagent MSTFA $+1 \%$ TMCS (Sigma-Aldrich, MO, USA) and pyridine (2:1) at $80^{\circ} \mathrm{C}$ for 1 hour, the sample was analyzed by GC/MS (Agilent GC7890A-MS5975C, Agilent Technologies, CA, USA) using the ion at $\mathrm{m} / \mathrm{z}$ (mass/charge) 217. The quantification was based on an external calibration procedure and the recovery was estimated spiking each filter with methyl $\beta$-Larabinopyranoside standard (Sigma-Aldrich, MO, USA), $6 \mu \mathrm{g}$ for winter and $1 \mu \mathrm{g}$ for summer added to each sample before extraction. The instrumental conditions are reported in Table 1.

\subsubsection{PAHs, PCDD/Fs and PCBs}

Part of the filter samples, spiked with ${ }^{13} \mathrm{C}_{12}$-labeled PCDD/Fs e PCBs and deuterate PAHs (Wellington Laboratories Inc., ON, CANADA), were extracted with a mixture of Acetone-Esano 50:50 v/v (pesticide grade, Fluka Sigma-Aldrich, MO, USA) by Dionex 350 ASE following the programme in Table 1. The concentrated extract was primarily cleaned by a chromatographic column packed with silica gel, to separate PAHs from PCBs and PCDD/Fs.

The PAHs fraction was evaporated under a stream of nitrogen, reconstituted with Syringe Standard in toluene and analyzed by GC-MS (Agilent GC7890A-MS5975C).

The PCBs and PCDD/Fs fraction was further cleaned up using a chromatographic column packed with alumina to separate PCBs from PCDD/Fs. The PCBs and PCDD/Fs were evaporated under a stream of nitrogen, reconstituted with the respective Syringe Standard in isooctane. The analysis was performed on an Agilent 7000 Triple quadrupole with an Agilent 7890GC (Agilent Technologies, CA, USA). The instrumental conditions are reported in Table 1.

\subsubsection{Metals}

Part of the filters are digested with $8 \mathrm{~mL}$ concentrated nitric acid $\mathrm{HNO}_{3}$ (Trace select ${ }^{\circledR}$ for trace analysis, Fluka

Table 1. Analytical conditions for PAHs, PCDD/Fs and PCBs in atmospheric particulate matter.

\begin{tabular}{|c|c|c|c|c|}
\hline & PAHs & $\mathrm{PCDD} / \mathrm{Fs}$ & PCBs & Levoglucosan \\
\hline Method extraction & ASE & ASE & ASE & ASE \\
\hline Solvent extraction & Acetone-Esano 50:50 v/v & Acetone-Esano 50:50 v/v & Acetone-Esano 50:50 v/v & $\begin{array}{l}\text { Dicholoromethane-methanol } \\
\qquad(80: 20 \mathrm{v} / \mathrm{v})\end{array}$ \\
\hline Condition extraction & $\begin{array}{l}\text { Oven Temp: } 130^{\circ} \mathrm{C} \\
\text { P: } 1500 \text { psi } \\
\text { Static Time: } 5 \mathrm{~min} \\
\text { Flush: } 50 \% \\
\text { Purge: } 120 \mathrm{sec} \\
\text { Static cycles: } 2\end{array}$ & $\begin{array}{l}\text { Oven Temp: } 130^{\circ} \mathrm{C} \\
\text { P: } 1500 \mathrm{psi} \\
\text { Static Time: } 5 \mathrm{~min} \\
\text { Flush: } 50 \% \\
\text { Purge: } 120 \mathrm{sec} \\
\text { Static cycles: } 2\end{array}$ & $\begin{array}{l}\text { Oven Temp: } 130^{\circ} \mathrm{C} \\
\text { P: } 1500 \mathrm{psi} \\
\text { Static Time: } 5 \text { min } \\
\text { Flush: } 50 \% \\
\text { Purge: } 120 \mathrm{sec} \\
\text { Static cycles: } 2\end{array}$ & $\begin{array}{l}\text { Oven Temp: } 100^{\circ} \mathrm{C} \\
\text { P: } 1500 \mathrm{psi} \\
\text { Static Time: } 4 \text { min } \\
\text { Flush: } 50 \% \\
\text { Purge: } 120 \mathrm{sec} \\
\text { Static cycles: } 2\end{array}$ \\
\hline Method determination & GC-MS & GC-MSMS & GC-MSMS & GC-MS \\
\hline Injection mode & Splitless $300^{\circ} \mathrm{C}$ & $\begin{array}{c}\text { Pulsed Splitless } \\
90^{\circ} \mathrm{C}(0.05 \mathrm{~min}), \\
600^{\circ} \mathrm{C} / \mathrm{min}-325^{\circ} \mathrm{C}\end{array}$ & $\begin{array}{c}\text { Splitless } \\
100^{\circ} \mathrm{C}(0.05 \mathrm{~min}), \\
600^{\circ} \mathrm{C} / \mathrm{min}-320^{\circ} \mathrm{C}\end{array}$ & $\begin{array}{l}\text { Split 20:1 } \\
260^{\circ} \mathrm{C}\end{array}$ \\
\hline Carrier gas & Helium $1.2 \mathrm{ml} / \mathrm{min}$ & Helium $1.2 \mathrm{ml} / \mathrm{min}$ & Helium $1.1 \mathrm{ml} / \mathrm{min}$ & Helium $1.1 \mathrm{ml} / \mathrm{min}$ \\
\hline Oven program & $\begin{array}{c}90^{\circ} \mathrm{C}(2 \mathrm{~m})-10^{\circ} \mathrm{C} / \mathrm{m} \\
-300^{\circ} \mathrm{C}(15 \mathrm{~m})-10^{\circ} \mathrm{C} / \mathrm{m} \\
-320^{\circ} \mathrm{C}(17 \mathrm{~m})\end{array}$ & $\begin{array}{c}70^{\circ} \mathrm{C}(0.5 \mathrm{~m})-25^{\circ} \mathrm{C} / \mathrm{m} \\
-200^{\circ} \mathrm{C}(6 \mathrm{~m})-5^{\circ} \mathrm{C} / \mathrm{m} \\
-250^{\circ} \mathrm{C}(15 \mathrm{~m})-10^{\circ} \mathrm{C} / \mathrm{m} \\
-300^{\circ} \mathrm{C}(6 \mathrm{~m})-10^{\circ} \mathrm{C} / \mathrm{m} \\
-325^{\circ} \mathrm{C}(1 \mathrm{~m})\end{array}$ & $\begin{array}{c}70^{\circ} \mathrm{C}(1 \mathrm{~m})-25^{\circ} \mathrm{C} / \mathrm{m} \\
-200^{\circ} \mathrm{C}(1 \mathrm{~m})-1^{\circ} \mathrm{C} / \mathrm{m} \\
-240^{\circ} \mathrm{C}(1 \mathrm{~m})-20^{\circ} \mathrm{C} / \mathrm{m} \\
-290^{\circ} \mathrm{C}(7 \mathrm{~m})\end{array}$ & $\begin{array}{c}80^{\circ} \mathrm{C}(2 \mathrm{~m})-10^{\circ} \mathrm{C} / \mathrm{m} \\
-280^{\circ} \mathrm{C}(5 \mathrm{~m})\end{array}$ \\
\hline Column & $\begin{array}{l}\text { Like DB5 } 60 \mathrm{~m} \times 0.25 \mathrm{ID} \text {; } \\
0.25 \mu \mathrm{m}\end{array}$ & $\begin{array}{c}\text { Like DB5 } 60 \mathrm{~m} \times 0.25 \mathrm{ID} \text {; } \\
0.25 \mu \mathrm{m}\end{array}$ & $\begin{array}{l}\text { Like DB5 } 60 \mathrm{~m} \times 0.25 \mathrm{ID} ; \\
0.25 \mu \mathrm{m}\end{array}$ & $\begin{array}{c}\text { Like DB5 } 60 \mathrm{~m} \times 0.25 \text { ID; } \\
0.25 \mu \mathrm{m}\end{array}$ \\
\hline MS condition & EI-SIM & EI-MRM & EI-MRM & EI-SIM \\
\hline
\end{tabular}


Sigma-Aldrich, MO, USA) and $2 \mathrm{ml}$ of Hydrogen Peroxide $\mathrm{H}_{2} \mathrm{O}_{2}$ (Trace Select ${ }^{\circledR}$ Ultra $\geq 30 \%$, Fluka Sigma-Aldrich, MO, USA) in a micro-wave digestion system (Start E, Milestone, CT, USA). The acid solutions diluted with ultrapure-MilliQ water, were analyzed by Atomic Absorption Spectrometer (AANALYST 600, Perkin-Elmer, MA, USA). Metals are discussed briefly in this article.

\subsubsection{Organic and Elemental Carbon}

On the other filter EC/OC was analyzed using Thermal Optical Carbon Analyzer (SunSet Lab. Inc., OR, USA) following NIOSH-like protocol.

\section{Results}

The results of the PM10 monitoring campaign made during 2013-2014 in the Region are shown below.

In Figure 2 the average seasonal concentration of PAHs and levoglucosan measured in 11 sample sites of the network is shown: the high seasonality observed for PAHs is due to the domestic heating during winter time and to the different meteorological conditions that, during summer, cause PAHs photodegradation and an easier atmospheric dispersion of pollutants.

The high seasonality of levoglucosan confirms its characteristic of biomass burning marker.

The levoglucosan is indeed well correlated with those congeners of PAHs that literature studies attribute to the prevailing domestic heating source such as Benzo[ $\alpha]$ Pyrene (BaP) (CASRN 50-32-8) | IRIS | US EPA and Benzo $[\alpha]$ Anthracene (CASRN 56-55-3) | IRIS | US EPA ( $\mathrm{R}^{2}$ from 0.91 to 0.93 ) and less correlated with those congeners that are more related to the vehicle traffic like Fluoranthene (CASRN 206-44-0) | IRIS | US EPA and Pyrene (CASRN 129-00-0) | IRIS | US EPA $\left(\mathrm{R}^{2}=0.70\right)$, Figure 3. Moreover the Indeno [1]-[3] Pyrene (CASRN 193-39-5) | IRIS | US EPA /Benzo[ghi]Perylene (CASRN 191-24-2) | IRIS | US EPA ratio estimated in all sites ranged from 0.7 to 1.2 , typical of diesel engine [8].

Figure 4 shows the seasonal average concentrations of PCDD/Fs (fg (I-TEF) $/ \mathrm{m}^{3}$ ) and PCB pg $/ \mathrm{m}^{3}$ in PM10 for different sites in the network. With the exception of the site of Amelia, for which a high value during the autumn

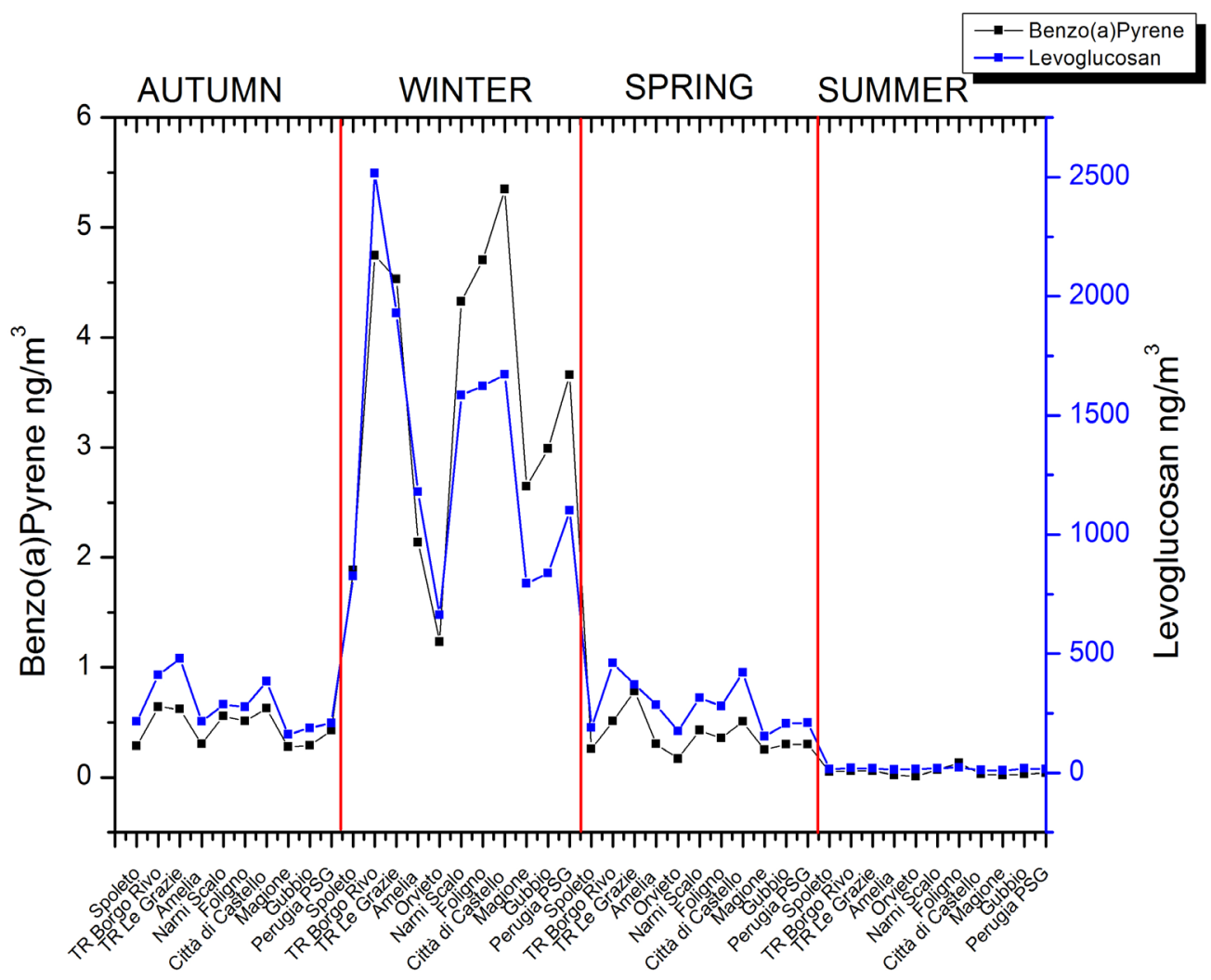

Figure 2. Average seasonal concentration of PAHs and levoglucosan in 11 regional sampling sites. 


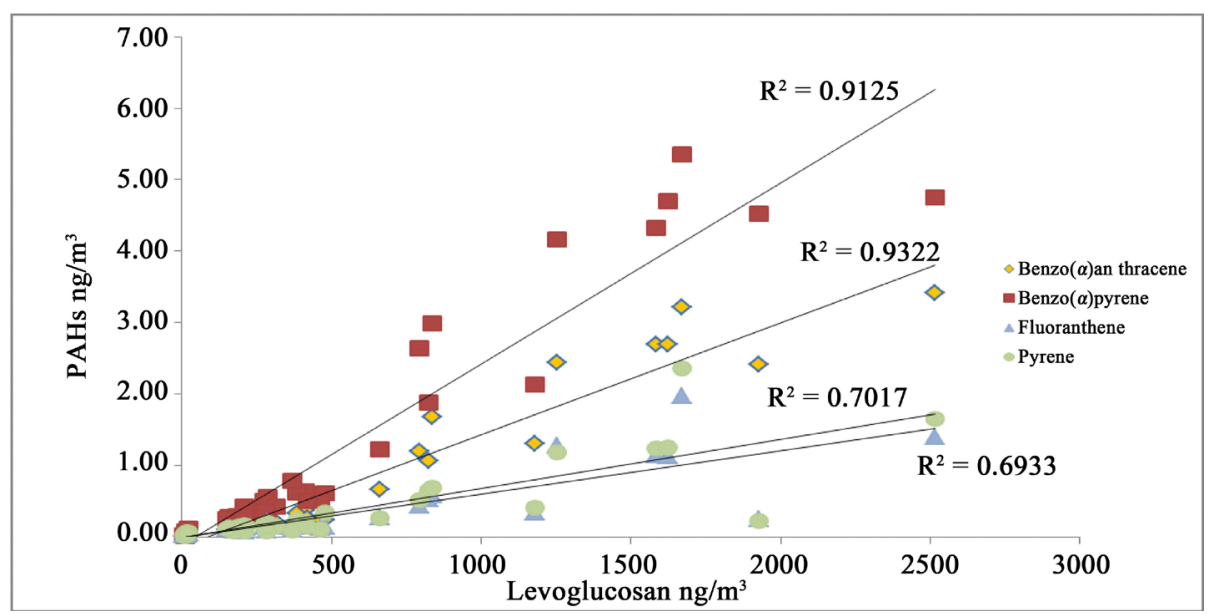

Figure 3. Correlation plot levoglucosan vs. different PAHs.

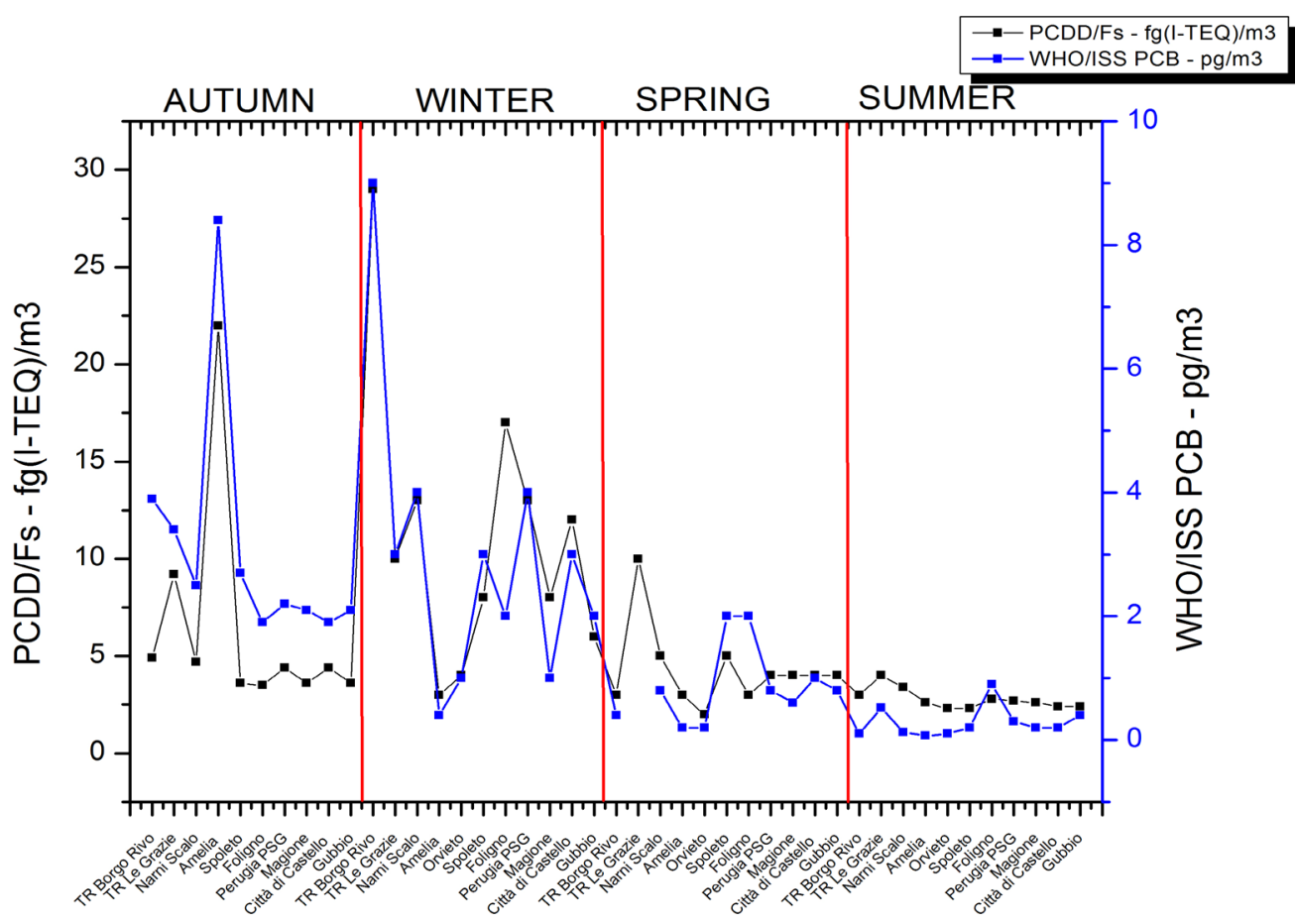

Figure 4. Average seasonal concentration of PCDD/Fs and PCBs in 11 regional sampling sites.

season was measured, the trend appears to be aligned with that of the PAHs. To explain this anomaly has been suggested the influence of a source such as a localized and temporary uncontrolled fire of agricultural waste. The repetition of the measure in the same season the following year provided PCDD/Fs and PCBs concentrations completely normal.

Figure 5 shows the levoglucosan correlation with PAHs, PCDD/Fs and PCBs. From the graph it is clear that there is a high degree of correlation between levoglucosan and PAHs confirming a common source of emission (combustion of Biomass) and a lower degree of correlation between levoglucosan, PCDD/Fs and PCBs to indicate the possible influence of other sources.

The anthropization of "Conca Ternana”, urban sites of Terni and sub-urban site near Terni (Narni), is even more evident if the comparison is made between the concentrations of some metals in PM10. As an example is shown in Figure 6 the diagram that relates chromium and nickel in different monitoring sites during the reference period. Where there is the steel production plant the values of the two metals are very high, this fact stands 


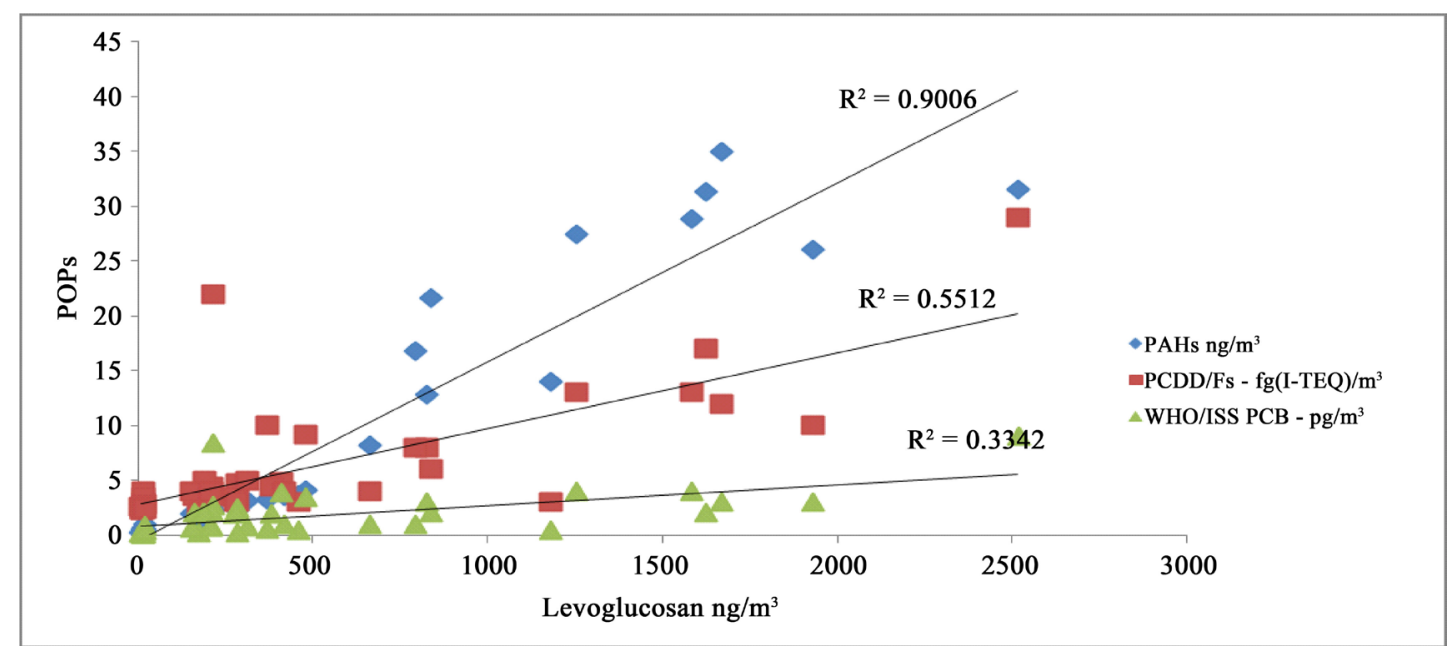

Figure 5. Correlation plot levoglucosan vs. different PAHs, PCDD/Fs and PCBs.

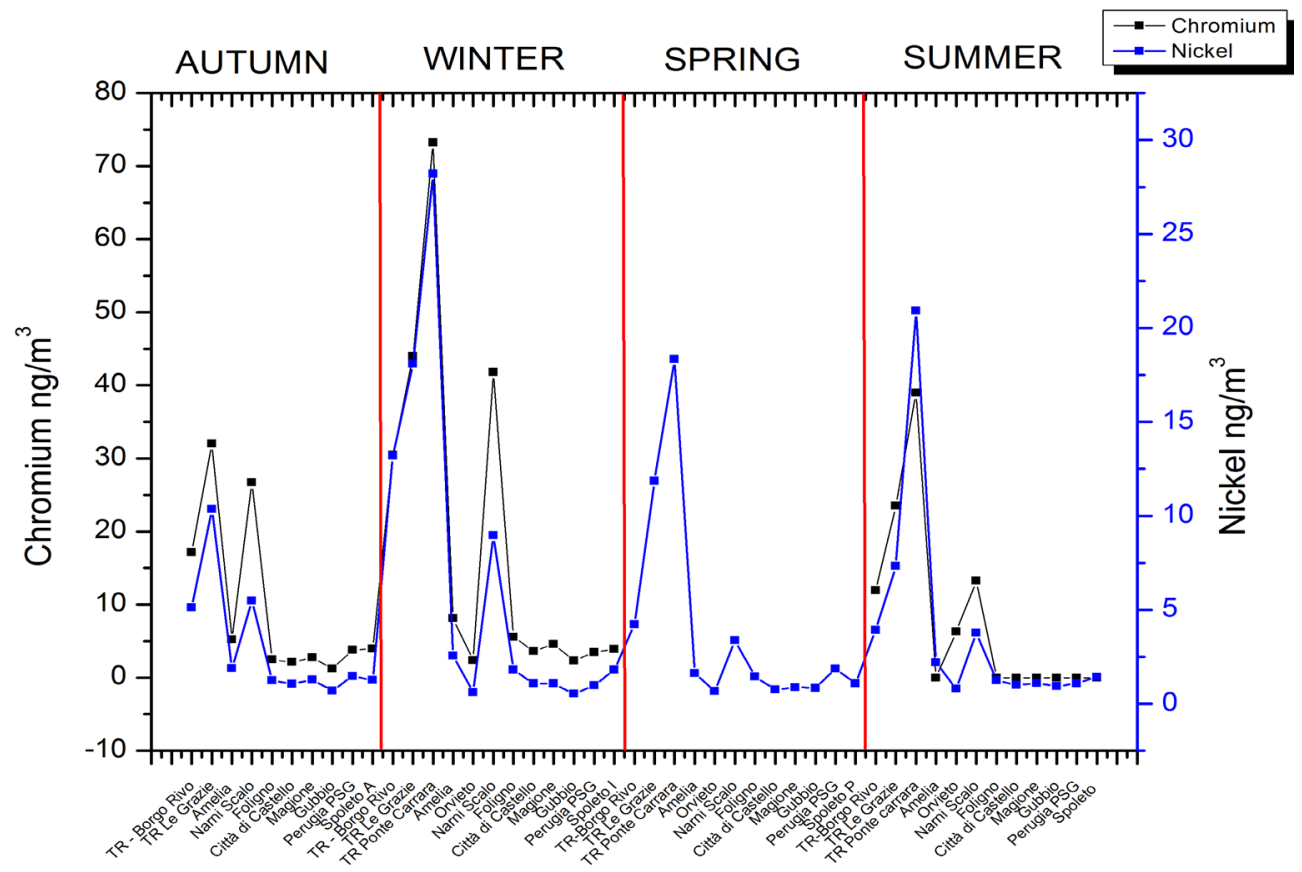

Figure 6. Average seasonal concentration of chromium and nickel in 11 regional sampling sites.

out most of the seasonality. These two metals are closely related between them $\left(\mathrm{R}^{2}=0.91\right)$ demonstrating a common source of emission.

About OC/EC were selected urban background samples (AM: Amelia, CC: Città di Castello, PC: Perugia) and rural background samples (MM: Monte Martano). The high value of the ratio OC/EC in rural background is likely due to a strong biogenic components in the OC, the EC values (traffic marker) are very low in these samples as we can expect in a rural background; the low value of the ratio OC/EC in PC can be explained by a greater contribution of EC instead. The other two sampling points are placed in intermediate positions; the three urban backgrounds are ideally located along a line, the rural background shows values completely different (Figure 7).

\section{Conclusions}

In conclusion about the analysis of PAHs, PCDD/Fs, PCBs and levoglucosan in PM10 for the year 2013-2014, 


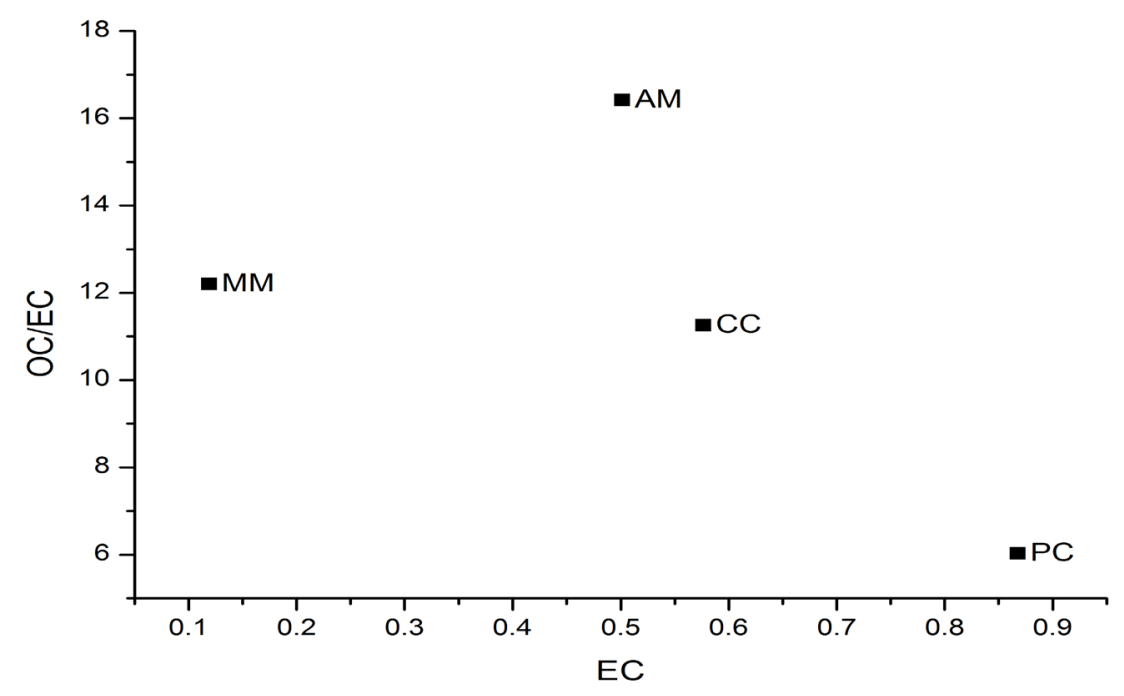

Figure 7. Elemental carbon vs organic carbon/elemental carbon ratio.

we can say that:

- All these parameters have concentrations far higher in cold seasons due to the additional contribution of domestic heating and the smaller dispersion of pollutants into the atmosphere during such seasons. In Terni basin, where a major industrial plant insists, on average higher concentrations than the rest of the region are detected.

- Even in smaller urban centers, significant concentrations of PAHs are measured and good correlation with the concentration of levoglucosan suggests an important contribution of biomass combustion source.

Further analysis is carried on and a confirmation of what was found by the present study is expected.

\section{References}

[1] Kim, K.-H., Kabir, E. and Kabir, S. (2015) A Review on the Human Health Impact of Airborne Particulate Matter. Environment International, 74,136-143. http://dx.doi.org/10.1016/j.envint.2014.10.005

[2] Rani, B., Singh, U., Chuhan, A.K., Sharma, D. and Maheshwari, R. (2011) Photochemical Smog Pollution and Its Mitigation Measures. Journal of Advanced Scientific Research, 2, 28-33.

[3] Moroni, B., Cappelletti, D., Marmottini, F., Scardazza, F., Ferrero, L. and Bolzacchini, E. (2012) Integrated Single Particle-Bulk Chemical for the Characterization of Local and Long Range Sources of Particulate Pollutants. Atmospheric Environment, 50, 267-277. http://dx.doi.org/10.1016/j.atmosenv.2011.12.022

[4] Belis, C., Larsen, B., Piazzalunga, A., Vecchi, R., Colombi, C. and Vorne, G. (2010) The Contribution of Biomass Burning to PAH Levels in PM10. Geophysical Research Abstract, 12EGU2010-13018-2.

[5] Caricchia, A.M., Chiavarini, S. and Pezza, M. (1999) Polycyclic Aromatic Hydrocarbons in the Urban Atmospheric Particulate Matter in the City of Naples (Italy). Atmospheric Environment, 33, 3731-3738. http://dx.doi.org/10.1016/S1352-2310(99)00199-5

[6] Menichini, E., Iacovella, N., Monfredini, F. and Turrio-Baldassarri, L. (2007) Atmospheric Pollution by PAHs, PCDD/Fs and PCBs Simultaneously Collected at a Regional Background Site in Central Italy and at an Urban Site in Rome. Chemosphere, 69, 422-434. http://dx.doi.org/10.1016/j.chemosphere.2007.04.078

[7] Simoneita, B.R.T., Schauerb, J.J., Nolteb, C.G., Orosa, D.R., Eliasa, V.O., Fraserb, M.P., Roggec, W.F. and Cassb, G.R. (1999) Levoglucosan, a Tracer for Cellulose in Biomass Burning and Atmospheric Particles. Atmospheric Environment, 33, 173-182. http://dx.doi.org/10.1016/S1352-2310(98)00145-9

[8] Ravindra, K., Sokhi, R. and Van Grieken, R. (2008) Atmospheric Polycyclic Aromatic Hydrocarbons: Source Attribution, Emission Factors and Regulation. Atmospheric Environment, 42, 2895-2921.

http://dx.doi.org/10.1016/j.atmosenv.2007.12.010 